\title{
Otizmli Çocuğa Sahip Ailelerin Yaşadıkları Zorluklara İlişkin Deneyimleri
}

DOI: 10.26466/opus.923379

\author{
Ferhat Toper * - Yasemin Özkan** \\ * Dr. Öğr. Üyesi, Malatya Turgut Özal Üniversitesi, Sağlık Bilimleri Fakültesi, Malatya/Türkiye \\ E-Posta: ferhat.toper@ozal.edu.tr \\ ORCID: $\quad \underline{0000-0001-6398-5343}$ \\ ** Prof. Dr. Yasemin Özkan, Hacettepe Üniversitesi, İ̈BF, Ankara/Türkiye \\ E-Posta: ymozkan@gmail.com \\ ORCID: $\quad$ 0000-0002-2968-363X
}

Öz

Otizm belirtilerinin erken çocukluk döneminde ortaya çıkan ve etkileri genellikle bir ömür süren geniş spektrumlu nöro-gelişimsel bir bozukluktur. Otizmin küresel yaygınlı̆̆ her geçen yıl katlanarak artmakta ve bu durum otizmli birey ve ailelerini odak alan çalş̧malar daha önemli hale gelmektedir. Zira otizm sadece bireyin değil aile üyelerinin iyilik halini de ciddi anlamda etkileyen bir bozukluktur. Başta bakım ile ilgili yükler olmakla birlikte aileler üzerindeki psikolojik ve sosyal yükler, aile dinamiklerini etkilemektedir. Bu çalı̧̧manın amacı da otizmli çocuğa sahip ailelerin yaşadıkları psikolojik ve sosyal zorluklara ilişkin deneyimlerini ortaya koymak ve ihtiyaçların belirlemektir. Araştırma, ailelerin otizmli çocuğa sahip olma konusundaki hislerini, deneyimlerini ve alğlarım keşfetmek amacıyla nitel olarak tasarlanmıştır. Bu amaç doğrultusunda 18 yaş altı çocukları için tıbbi anlamda otizm tanısı almış 10 ebeveyn ile derinlemesine görü̈smeler gerçekleştirilmiştir. Çalışma grubunun belirlenmesinde amaçl örneklem kullanılmıştır. Veriler yarı yapılandırılmış görü̈sme formu kullanılarak araştırmacı tarafından gerçekleştirilen yüz yüze görüşmeler neticesinde elde edilmiş ve MAXQDA 2020 programı ile analiz edilmiştir. Ailelerin tanı öncesi, tanı sonrası ve sosyal kabul ile ilgili çeşitli zorlukları bulunmaktadır. Ailelerin şüphe duydukları an ile tanı almak için profesyonellere gitme süreleri arasında geçen sürenin uzaması zorluklar arasındadır. Bu durum kabullenmeme ve inkâr ile ilgilidir. Tan sonrası kabullenmekte zorlanan aileler bu süreçte farklı profesyonellere gitmekte ve bu durum erken müdahale ve eğitimle ilgili gecikmelere neden olmaktadır. Aileler tanı sonrası ne yapacakları ile ilgili net bir yol haritasına sahip olmamayı ve aile bilgilendirmesinin oldukça yeteriz olduğunu belirtmişlerdir.

Anahtar Kelimeler: Otizm, Sosyal Destek, Sosyal Hizmet, Psikolojik Yük. 


\title{
The Experiences of Families with Autistic Children with Their Difficulties
}

\begin{abstract}
It is a broad-spectrum neurodevelopmental disorder that manifests symptoms of autism in early childhood and its effects usually last a lifetime. The global prevalence of autism increases exponentially with each passing year, and studies focusing on individuals with autism and their families are becoming more important. Because autism is a disorder that seriously affects not only the individual but also the well-being of family members. Although there are burdens related to care, psychological and social burdens on families affect family dynamics. The aim of this study is to reveal the experiences of families with children with autism regarding psychological and financial difficulties and to determine their needs. The research was qualitatively designed to explore families' feelings, experiences and perceptions about having a child with autism. For this purpose, in-depth interviews were conducted with 10 parents who were medically diagnosed with autism for their children under the age of 18. Purposeful sampling was used to determine the study group. The data were obtained as a result of face-to-face interviews conducted by the researcher using a semi-structured interview form and analyzed with the MAXQDA 2020 program. Families have various difficulties regarding prediagnosis, post-diagnosis and social acceptance. Difficulties include the prolongation of the time between the moment when families are in doubt and the time they go to professionals for a diagnosis. This is about non-acceptance and denial. Families who have difficulties in accepting after the diagnosis go to different professionals during this process, which causes delays in early intervention and education. The families stated that they do not have a clear road map about what to do after the diagnosis and that informing the family is quite sufficient.
\end{abstract}

Key Words: Autism, Social Support, Social Work, Psychological Burden. 


\section{Giriş}

Otizm spektrum bozukluğu, belirtileri erken çocukluk döneminde ortaya çıkan ve genellikle etkileri ömür boyu süren, sosyal etkileşim ve iletişim becerilerini olumsuz yönde etkileyen nöro-gelişimsel bir bozukluktur. Otizm, Yunanca'da "autos" yani "kendilik" anlamina gelmektedir.

Bleuler 1950'li yıllarda bu terimi şizofreni tanılı hastaların kendilerini dış dünyadaki algı ve deneyimlerden soyutlayarak iç dünyalarına çekilmelerini tanımlamak için kullanmıştır (Kuhn and Cahn, 2004, s.361). Bleuler bu dönemde otizmi, "gerçek dünya ve gerçeklikle ilişki kurma bozukluğu" olarak nitelendirmiş ve bu durumu "çocukluk şizofrenisi" olarak adlandırmıştır (Kayaoğlu and Görür, 2008, s.27).

Ruhsal Bozuklukların Tanısal ve İstatistiksel El Kitabı (5. baskı, DSM5, Amerikan Psikiyatri Birliği 2013), Otizm Spektrum Bozukluğunu, sosyal iletişim ve sosyal etkileşim bozukluğu ile "kısıtlı, tekrarlayan davranış kalıpları, ilgi alanları veya faaliyetler" şeklindeki iki alanda yaşanan bozukluklar şeklinde tanımlamaktadır (APA 2013).

İlk olarak 1943 y1lında John Hopkins Üniversitesinde psikiyatr olan Leo Kanner'in kullanmış olduğu otizm kavramı, çevresel, ailesel ve genetik nedenlerden kaynaklanan bir bozukluk olarak tanımlanmıştır (Volkmar and Lord, 2007, s.2; Çolak, 2016, s.22). Aradan geçen onca yılın ardından yapılan sayısız çalışmalar, otizmi, bireyin sosyal ilişkilerini, iletişim becerilerini ve davranışlarını olumsuz yönde etkileyen nörogelişimsel bir bozukluk olduğunu ortaya koymuştur.

Otizm, yaşamın ilk yıllarında ortaya çıkan ve göz kontağı kurma, ortak dikkat ve işaret etme davranışlarındaki yetersizliklerle kendini belli eden ve genellikle hayatın ilk 3 yılında hatta bazen daha erken dönemde ortaya çıkan nörobiyolojik ve nöropsikiyatrik bir bozukluktur (Baker, 2013). Otizm, sosyal etkileşim ve iletişim bozukluklarının yanı sıra sosyal davranış, stereotip davranış ve ilgiler ile dil gelişimindeki yetersizliklerle kendini gösteren ve etkileri yaşam boyu sürebilen, nörobiyolojik bir bozukluktur.

Otizmin nedeni yıllardır birçok alandan bilim insanı tarafından merak edilmiş, psikoloji, tıp ve eğitim alanındaki bilim insanları başta olmak üzere çok sayıda bilimsel çalışma gerçekleştirilmiştir. Bu anlamda, otizmle ilgili olarak nörokimyasal, nörobiyolojik, nöroanatomik, 
nöropsikiyatrik gibi alanlarda yapılan pek çok araştırma sonuçları bulunmaktadır (Köse Özbaran ve Erermiş, 2012, s.103). Çalışmalar otizmin sık görülen nöropsikiyatrik bozukluklar arasında yer aldığını ortaya koymuşsa da nedeni henüz aydınlatılamamış ve ana belirtileri üzerine iyileştirici etkisi olan bir tıbbi tedavi bulunamamıştır (Bilgiç and Cöngöloğlu, 2009, s.154). Birçok farklı nedeni olduğu ortaya çıan otizm ile ilgili araştırmalardan çıkan en önemli sonuç; otizm spektrum bozukluğunun tek bir tip olmadığı gibi oluş sebebinin de tek bir nedene bağlanamayacağıdır.

Otizmin neden kaynaklandığına ilişkin pek çok fikir öne sürülmüştür. Bazı araştırmacılar beyinde çevreden gelen uyarıcıların işlendiği bölgedeki işlevsel bozukluklar ve beynin temporal bölgesindeki hasarın otizme neden olabileceğini iddia etmişlerdir. Genetik alanında çalışan araştırmacılar ise otizmin genetik etmenlerin rol oynadığını savunmuşlardır (Frith, 2008, s.54).

Otizmin etiyolojik etmenleri arasında genetik hastalıklar, nöroanatomik faktörler, natal faktörler, nörokimyasal faktörler, immün faktörler, çevre faktörü ve genetik faktörler sayılmaktadır (Yüksel, 2005, s.36). Otizmin risk etmenleri arasında gluten içeren besinler, ağır metallere maruziyet, vitaminler, enfeksiyonlar, anne-baba yaşı, alkol ve madde bağımlılığ 1 vb. birçok etmene değinilmiştir (Baker, 2013, s. 44).

Özet olarak otizmin belli bir nedenden kaynaklanmadığını, genetik ve çevresel faktörler gibi birçok etmenin etkileşimsel olarak karmaşık bir gelişimsel nörolojik bozukluk olarak kendini gösterdiğini söyleyebiliriz (Çolak, 2016, s.33; Şener ve Özkul, 2013, s.89).

Otizmle ilgili bir diğer konu otizmin yaygınlığı ve son yıllarda olağanüstü bir şekilde artışıdır. Otizmin, zihin engelinden sonra en yaygın görülen gelişimsel bozukluk olduğu bilinmektedir (Wing and Potter, 2002, s.159). Ayrıca otizm, dünya üzerinde bulunan tüm ırk, etnik grup ve sosyal statüden toplumda görülmektedir (Korkmaz, 2010). 1960'lardan bu yana otizmin yaygınlığındaki olağanüstü artış, başta tıp ve psikoloji olmak üzere birçok farklı sosyal bilim araştırmacılarının dikkatini çekmiştir. Otizmin yaygınlığı ile ilgili ilk çalışma, 1966 yılında Victor Lotter tarafından yapılmış ve yapılan bu ilk çalışmada otizmin yaygınlığ1 10.000'de 4,5 olarak ortaya konmuştur (Lotter, 1966, s.125). 
Baird ve arkadaşları (2006) Lancet'de yayınlanan çalışmalarında otizmin yaygınlığ1 ile ilgili 1990'lara kadar 10.000'de 20 vakaya kadar farklı yaygınlık araştırmaları bulunsa da genel olarak 10.000 'de $4-5$ olarak kabul edildiğini belirtmişlerdir (Baird, ve diğerleri, 2006, s.211).

Amerika Birleşik Devletleri Hastalık Kontrol ve Önleme Merkezi (CDC-Centers for Disease Control and Prevention) tarafından oluşturulan Otizm ve Gelişimsel Bozuklukları İzleme Ağı (ADDM-NET Autism and Developmental Disabilities Monitoring Network) otizmin yaygınlığının 2000 yılında 1/150, 2006 yılında 1/110, 2012 yılında 1/69, 2014 yılında 1/59 ve 2016 yılında 1/54 olarak açıklamıştır (National Autism Center at MayInstitute, 2020).

Otizm, bireysel bir gelişimsel bozukluk olmaktan ziyade tüm aile üyelerini belirli düzeylerde etkilediği için otizmle ilgili çalışmalarda, otizmin aile sistemine olan etkisi üzerinde sıklıkla durulmaktadır. Genel olarak aileye yeni bir üyenin katılımı ve bu yeni üyenin aileye adaptasyonunun en kısa sürede sağlanması tercih edilen bir durum olsa da bu her zaman için mümkün olmamaktadır. Özellikle yetersizliği olan bir bireyin aileye katılması çoğu zaman aileler için zorlu bir süreç haline gelmektedir. Bu durum, ailenin üzerine çok daha fazla sorumluluk yüklediği için stres kaynağı olarak karşımıza çıkmaktadır.

Gelişimsel geriliği olan bir çocuğa sahip ailelerin, normal gelişim gösteren çocuğa sahip aileler ile karşılaştırıldığında, daha depresif ve sosyal olarak izole oldukları bildirilmiştir (Benderix, Nordström, \& Sivberg, 2006; Gupta, 2007). Ayrıca çalışmalar, otizmli çocuğa sahip ailelerin, normal gelişim gösteren çocuklar ve diğer engelli çocukların ailelerinden daha fazla ebeveynlik stresi yaşadığını ortaya koymuştur. $\mathrm{Bu}$ stres genellikle çocuklarının ihtiyaçları karşılamanın zorluklarıyla ilgilidir (Hayes and Watson, 2013; Ooi, Mehmood, Khan and Tahir, 2016). Bu durum otizmli çocukların ihtiyaçları, eğitim ve tedavi ile ilgili zorlukları ve toplumsal kabul ile ilgili olabildiği gibi sosyal destek ve bakım yükü ile de ilgili olabilmektedir.

Hem çocuk hem de aile üzerinde yaşam boyu etkileri süren en ciddi gelişimsel engellerden biri olan otizm spektrum bozukluğu olan çocuğa sahip ailelerin, normal gelişim gösteren çocuğa sahip ailelere göre çok daha fazla tükenmişlik yaşadıklarını, daha yüksek düzeyde strese 
altında olduklarını, psikolojik ve fiziksel sorunlar yaşadıkları ortaya konmuştur (Dyches, Wilder, Sudweeks, Obiakor and Algozzine, 2004; Lee, Harrington, Louie and Newschaffer, 2007). Ebeveynler bakım yükü ve yetersiz sosyal destek dolayısıyla psikolojik iyilik hallerini kaybetmekte ve yaşadıkları stresle bağlantılı olarak farklı sağlık sorunları ile karşı karşıya kalabilmektedirler.

Ayrıca otizmli çocuğa sahip ailelerin, gelecekle ilgili çok daha fazla kötümserlik gösterdikleri ve otizmin şiddetinin artmasının ailedeki stres düzeyini de doğrudan etkilediği belirtilmiştir (McGrath, 2006, s.30). Marcus, Kunce ve Schopler (2005), otizmli çocuğa sahip ailelerin artan stres yükü altında olmalarını belirli etmenler özelinde açıklamışlardır. İlk olarak aile, karmaşık bir tanı sürecinden geçmekte ve tanı sonrasında neler yapacakları veya yapmaları gerektiği ile ilgili net bir yol haritasına sahip olmadıklarından dolayı ciddi bir belirsizlikle karşı karşıya kalmaktadır (Marcus, Kunce and Schopler, 2005). Otizm, diğer bazı gelişimsel gerilikler gibi doğumdan hemen sonra hatta ve hatta doğum öncesinde belli tetkiklerle ortaya konan ve teşhis edilebilen bir gelişimsel gerilik değildir. Örneğin down sendromlu bir çocuğa sahip ebeveynler, doğumla birlikte hatta daha anne karnında, çocuklarının down sendromlu olduğunu öğrenebilmektedir. Ancak otizmde sebeplerin belirsizliği ve tanı sürecinin uzaması, ailelerde belirsizliğin getirdiği bir strese neden olmaktadır.

Ailelerin stresini arttıran ikinci etmen ise çocukların gelişiminin tutarsız oluşu ve bu durumun ailelerde kafa karışıklığına yol açmasıdır. Çocuklar belli yaşlara kadar yaşıtları ile benzer gelişim seyri içerisindeyken belli bir yaştan sonra duraksamakta, bazen de gerilemeler yaşamaktadır. Bu durum ise aileler için içinden çıkılması zor bir hal almaktadır (Marcus, Kunce and Schopler, 2005).

Aileler için bir diğer stres etmeni ise çocuklarının normal gelişim gösteren çocuklarla aynı diş görünüşe sahip olmalarına rağmen akranlarıyla benzer tutum ve davranışları sergileyememesidir. Toplum içerisinde sergilenen bazı problemli davranışlar, çocukların normal gelişim gösteren çocuklarla benzer görünüşe sahip olmasından dolayı toplum tarafından yadırganmakta, eleştirilmektedir. $\mathrm{Bu}$ durum ise ailelerin utanma ve çocuklarını kontrol edemeyen ebeveynler gibi 
hissetmelerine ve dolayısıyla stres yüklerinin artmasına neden olmaktadır (Marcus, Kunce and Schopler, 2005, s.1058).

Otizmli çocuğa sahip aileler yukarıda belirtilen etmenlere ek olarak çocuklarının ilerleyen yaşlarda kendilerine yetecek ve öz yaşam becerilerini kazanacak bireyler olabilmesi için başta öğretmenlik ve savunuculuk dolayısıyla avukatlık gibi birçok role bürünmek zorunda kalmaktadırlar. Tüm bu nedenlerden dolayı otizmli çocuğa sahip ailelerin psikolojik ve duygusal olarak sağlıklı olmalarının yanında fiziksel olarak da sağlıklı olmaları oldukça önemlidir (Kaya, 2016, s.293). Zira aile ne kadar güçlü ise çocuk için o denli güçlü ve etkili savunucular olabilirler

Aileler farkındalık ve tanılama sürecinde de çeşitli zorluklarla karşı karşıyadır. İlk olarak farkındalık sürecinde aileler çocuklarıyla ilgili farklılıkları ve gecikmeleri görseler dahi kabullenmek istememektedirler. Çevrelerinde bu farklılığa dikkat çeken ve kendilerine bu farklılıkla ilgili söylemlerde bulunan geniş aile üyeleri ve arkadaş çevresinden kişilere karşı öfkelenmekte ve kendilerini izole etmeye çalışmaktadırlar (Kaya, 2016, s.294).

Tanılama süreci de aileler için en az farkındalık süreci kadar zorlu geçmektedir. Aileler bu süreçte farklı uzmanlar tarafından farklı değerlendirmelere tabi tutulmakta ve bu durum sürecin uzamasıyla birlikte ailelerin duygusal ve maddi olarak zorluklar yaşamasına neden olmaktadır. Aileler farklı bir şey duyabilmek adına farklı uzman görüşlerine başvurmakta ve bu durum şüphe ile tanı arasında geçen sürenin artmasına neden olmaktadır. Tanılama sürecinde aileler ortalama 4-5 uzmana başvurmakta ve bu durum ortalama 3 yıl sürmektedir (Keen, Couzens, Muspratt, \& Rodger, 2010; Ailing-Moh \& Magiati, 2012).

İngiltere'de 1200 aile ile yapılan bir çalışmada, ailelerin neredeyse yarısının (\%48) ilk 24 ay içerisinde şüphe duymalarına rağmen ortalama 5 yaşında tanı aldıklarını ortaya koymuştur (Howlin and Moore, 1997, s.142). Tanılama sürecinde yaşanan bu gecikmeler, ailelerdeki çaresizlik, belirsizlik ve kaygıyı arttırdığı gibi uygun erken müdahalenin de gecikmesine neden olmaktadır. Bu belirsizlik ve en nihayetinde erken müdahale çabalarında yaşanan gecikmeler, ailelerin stresinin artmasına neden olmaktadır. (Midence and O'Neill, 1999, s.283). 
Otizmin göz ardı edilemeyecek denli hızlı artışı, desteğe ihtiyaç duyan başta otizmli birey ve aile sayısında artış yaşanmasına ve bu bireylerin yaşam kalitelerinin artırılması amacıyla koruyucu, önleyici ve destekleyici müdahaleler geliştirilmesini zorunlu kılmaktadır (Yılmaz and Atalar, 2021). Bu anlamda gerçekleştirilecek çalışmalar ve bu ailelerin sorun ve ihtiyaçlarının ortaya konması önem arz etmektedir.

\section{Problem}

Çocuk sahibi olmak tüm ebeveynler için beklenen ve özlenen bir durumdur. Ebeveynlerin doğacak çocukları ile ilgili umutları, beklentileri ve hayalleri vardır. Ancak normal gelişim göstermeyen çocuklarda bu hayaller ve beklentiler, öngörülemeyen zorluklar sebebiyle ulaşılamaz görünmeye başlar. Bu durum otizmli çocuğa sahip aileler için de geçerli bir durumdur. Zira otizmli çocuğa sahip aileler nerdeyse günün her saatini otizmli çocuğa adar ve günlük rutinlerini buna göre belirler. $\mathrm{Bu}$ da ailede başta ebeveynler olmak üzere diğer aile üyeleri için çeşitli zorlukların yaşanmasına neden olmaktadır.

Otizm, belirli bölgeler ve etnik gruplarla sınırlı olmayan bir gelişimsel yetersizliktir. Otizmin küresel yaygınlığı oldukça hızlı bir şekilde artmaktadır ve bu nedenle otizmi bir çocuğa sahip ailelerin deneyimlerinin tam olarak anlaşılması onlar için "en zor" olanın ne olduğunun bilinmesi çok önemlidir.

\section{Amaç}

Çalışmanın amacı, otizmli çocuğa sahip olmanın aile dinamikleri üzerindeki etkisini, aile üyelerinin yaşadığı zorlukları ortaya koymaktır. Ayrıca aileler için otizmli bir çocuk yetiştirmenin psikolojik ve sosyal etkisini anlamak ve aileler için sonuçlarını ortaya koymak araştırmanın amaçları arasındadır. Ebeveynlerin otizmli bir çocuğa sahip olmaktan dolayı fiziksel, duygusal ve zihinsel olarak nasıl etkilendiğini belirlemek de araştırmanın amaçları arasındadır. 
Araştırmanın amaçlarını şu şekilde sıralayabiliriz;

- Otizm Spektrum Bozukluğu teşhisi konmuş bir çocuğu yetiştiren ailelerin psikolojik ve sosyal açıdan ne tür zorluklar yaşadıklarını ortaya koymak

- Otizm Spektrum Bozukluğu olan bir çocuk yetiştirmenin ebeveynler üzerindeki psikolojik etkisini anlamak.

- Yarı yapılandırılmış görüşmeler yoluyla, ebeveynlerin Otizm Spektrum Bozukluğu olan bir çocuk yetiştirme konusundaki hislerini, deneyimlerini ve algılarını keşfetmek.

\section{Yöntem}

Araştırmanın Modeli: Araştırma, otizmli çocuğa sahip ailelerin yaşadıkları psikolojik ve sosyal zorluklarla ilgili deneyimlerini ortaya koymak amacıyla nitel bir araştırma olarak tasarlanmıştır. Nitel araştırma tasarımı sözcükler, açıklamalar, anlatılar ve gözlemler yoluyla ham verilerden bilgi üretir. Veri toplama, veri analizi ve bunların yorumlanması bu tasarımın bir parçasını oluşturur. Nitel araştırma, araştırmacının bir problem ile ilgili temel fikir, nedenler ve motivasyonunu anlamak adına kullandığı bir keşif araştırması olarak tanımlanabilir. Nitel araştırma, insanların hikâyelerinin, deneyimlerinin ve anlatılarının koleksiyonuna dayanmaktadır (Morse, 2016).

Araştırmada nitel araştırma desenlerinden biri olan fenomenolojik yaklaşım kullanılmıştır. Fenomenolojik yaklaşım bir grup insanın belirli bir konu ile ilgili deneyimlerini ele alan bir yaklaşımdır. Creswell (2013) fenomenolojik çalışmayı, belli insanların bir fenomen veya kavramla ilgili yaşadıkları deneyimlerinin ortak anlamını tanımlama ve neyin nasıl deneyimlendiğini bütünleştiren, bireylerin deneyimlerinin özünün tartışıldığı betimleyici bir çalışma olarak tanımlamaktadır (Creswell, 1994).

Çalışma Grubu: Nitel araştırmada örneklem büyüklüğünü belirlemek için belirli kurallar yoktur. Patton'a (2002) göre, “örneklem büyüklüğü bilmek istediklerinize, araştırmanın amacına, neyin tehlikede olduğuna, neyin yararlı olacağına, neyin güvenilirliğe sahip olacağına ve mevcut 
zaman ve kaynaklarla neler yapılabileceğine bağlıdır" (Fletcher, Markoulakis and Bryden, 2012, s.48).

Araştırmaya katılacak çalışma grubunun belirlenmesinde amaçlı örneklem kullanılmıştır. Amaçlı örneklem, araştırmanın problemine ve araştırmanın odağında yer alan fenomene uygun bilgiler vereceği tahmin edilen katılımcların seçimidir (Creswell, 2013). Patton (2014) ise amaçlı örneklemi, yapılan araştırmanın amaçlarını gerçekleştirmek için yeterli ve zengin bilgiye sahip olduğu düşünülen katılımcıların, çalışma grubu olarak seçilmesi şeklinde tanımlamaktadır (Patton, 2014).

$\mathrm{Bu}$ kapsamda araştırmanın çalışma grubunu otizmli çocuğa sahip 10 ebeveyn oluşturmaktadır. Çalışma grubunun belirlenmesinde ebeveynlerin çocukları için tıbbi olarak otizm tanısı almış olmaları ve çocuklarının 18 yaşından küçük olması kriter olarak alınmıştır. Araştırmaya katılımda gönüllülük esas alınmış ve katılımcılara araştırma hakkında bilgi veren ve onların onamlarının alındığı bilgilendirilmiş onam formu sunulmuştur. Ayrıca araştırmanın gerçekleştirilebilmesi için Hacettepe Üniversitesi Etik Komisyonu tarafından araştırmanın etik açıdan uygun olduğu yönünde uygunluk raporu alınmıştır.

Tablo 1. Çalışmaya katılan ebeveynler ve otizmli çocuğa ilişkin sosyo-demografik

\begin{tabular}{|c|c|c|c|c|c|c|}
\hline Ebeveyn & Yaş & $\begin{array}{l}\text { Eğitim } \\
\text { Durumu }\end{array}$ & Meslek & $\begin{array}{l}\text { Çocuğun } \\
\text { Yaşı }\end{array}$ & $\begin{array}{l}\text { Çocuğun } \\
\text { Cinsiyeti }\end{array}$ & $\begin{array}{l}\text { Görüşme } \\
\text { Süresi }\end{array}$ \\
\hline Baba-1 & 57 & Lise & Emekli & 15 & Erkek & $18.53 \mathrm{dk}$ \\
\hline Anne-1 & 53 & Üniversite & $\begin{array}{l}\text { Özel Sektörde } \\
\text { Yönetici }\end{array}$ & 13 & Erkek & $28.05 \mathrm{dk}$. \\
\hline Anne-2 & 34 & Üniversite & Öğretmen & 8 & Erkek & $26.06 \mathrm{dk}$. \\
\hline Baba-2 & 38 & Üniversite & Öğretmen & 9 & Erkek & $35.24 \mathrm{dk}$ \\
\hline Baba-3 & 48 & Doktora & Akademisyen & 16 & $\mathrm{~K}_{1 z}$ & $50.32 \mathrm{dk}$ \\
\hline Baba-4 & 39 & Üniversite & Optisyen & 8 & Erkek & $20.45 \mathrm{dk}$ \\
\hline Anne-3 & 55 & Üniversite & $\begin{array}{l}\text { Özel Sektörde } \\
\text { Yönetici }\end{array}$ & 16 & Erkek & $38.15 \mathrm{dk}$. \\
\hline Anne-4 & 35 & Üniversite & Sosyolog & 9 & Erkek & $55.02 \mathrm{dk}$ \\
\hline Baba-5 & 48 & Üniversite & İnşaat Mühendisi & 17 & Erkek & $43.15 \mathrm{dk}$ \\
\hline Baba-6 & 40 & Lise & Güvenlik Görevlisi & 10 & $\mathrm{~K} 1 \mathrm{z}$ & $42.40 \mathrm{dk}$ \\
\hline
\end{tabular}

Veri Toplama Araçları: Araştırmada, araştırmacı tarafından hazırlanan ve 16 sorudan oluşan sosyo-demografik özellikler formu ile yine araştırmacı tarafından hazırlanan ve 25 sorudan oluşan yarı yapılandırılmış görüşme formu kullanılmıştır. Sosyo-demografik 
özellikler formunda otizmli çocuğa yönelik tanıtıcı bilgiler ile ailenin yaş, gelir durumu, tanı alma yaşı vb. bilgilerin elde edilmesine yönelik sorular yer almaktadır. Aileler için hazırlanan yarı yapılandırılmış görüşme formunda ailenin otizmli bir çocuğa sahip olma ile ilgili tanı sürecinden eğitim ve rehabilitasyon sürecine, psikolojik ve sosyal açıdan yaşadıkları zorluklardan, eşler, kardeşler ve geniş aileye kadar yaşadıkları deneyimlerini anlamak amacıyla hazırlanan açı uçlu sorulardan oluşmaktadır.

Verilerin Analizi: Nitel araştırmada elde edilen verilerin analizi çeşitli basamaklardan oluşmaktadır. Toplanan ham veriler analiz için düzenlenmekte ve bu hazırlık sürecinde veriler tekrar tekrar okunmaktadır. Ebeveynlerle yapılan görüşmeler akıllı telefon aracılığı ile kayıt altına alınmış ve görüşülen 10 ebeveynin ses kayıtlarının transkripsiyonu yapılmıştır. Görüşmelerin toplam uzunluğu 6 saat 22 dakikadır. Ses dosyalarının ile derinlemesine görüşmeler 123 sayfalık metin dosya dönüştürülmüştür. Elde edilen veriler el ve bilgisayar yardımıyla gerçekleştirilerek temalar, betimlemeler ve birbirleri aralarındaki ilişkiler meydana getirilmekte ve yorumlanmaktadır (Creswell, 2013). Veriler daha sonra MAXQDA 2020 programina aktarılmıştır. Ara yüzü Türkçe olan, görsel analiz araçlarının yoğun bir şekilde kullanıldığı, temel istatistiksel analizlere ek olarak karma araştırma yöntemlerinde de kullanılabilen MAXQDA programı, elde yapılan analizlere göre verilerin daha sistematik bir şekilde çözümlenmesini sağlamaktadır (Kuckartz \& Rädiker, 2019).

MAXQDA 2020 programina aktarılan verilerin analiz sürecinde tümevarımcı bir yaklaşım benimsenmiştir. Veriler defalarca okunmuş ve ilk kodlar oluşturulmuştur. Ardından birbiri ile ilişkili kodlar temalar altında toplanarak isimlendirilmiştir. Elde edilen temalar literatür ile paralel ve anlaşılır bir dil ile açılanmıştır.

\section{Bulgular}

Araştırma kapsamında elde edilen veriler MAXQDA 2020 Nitel analiz programına aktarılmış, tüm veriler baştan sona okunarak kod listeleri oluşturulmuştur. Oluşturulan kod listeleri daha sonra 
kategorileştirilerek üç temel tema belirlenmiştir. Bu temalar, otizmli çocuğa sahip ailelerin tanı öncesi ve tanı sırası yaşanan zorluklar, tanı sonrası yaşanan zorluklar ve toplumsal kabul ile ilgili zorluklardır.

Tanı Öncesi ve Tanı Sırasında Yaşanan Zorluklar: Ebeveynler tanı öncesi ve tanı sırasında yaşanan zorluklarla ilgili başta şüphe duyma ve şüphe sonrası tanı sürecine girme ile ilgili zorluklardan, tanı ile ilgili netlik bulunmayışından, tanının kendilerine direkt olarak söylenmesinden, çoğu zaman tanının ne olduğunun net olarak ifade edilmeyişinden ve ailenin otizmin ne olduğu ile ilgili bilgi yetersizliğine kadar çeşitli zorluklardan bahsetmişlerdir. Bu anlamda tanı sürecinin uzaması, tanının aileye söylendiği ilk anda ailenin şok yaşaması, tanı ile ilgili geniş aile üyelerinden duyulan sözlere karşı verilen tepkiler, farklı bir şeyler duyabilmek adına farklı profesyonellere başvurmak için harcanan zaman ve bu süre içerisinde ailenin belirsizlik içerisinde oluşunu temel zorluklar arasında sayabiliriz. $\mathrm{Bu}$ konu ile ilgili ebeveynlerin görüşleri şu şekildedir;

"...Daha çocuk içeri adım atar atmaz doktor sizi neredeydiniz şimdiye kadar dedi, ardından direkt yüzümüze, sizin çocukta atipik otizm var dedi. Nutkumuz tutuldu. [...] Neyse ben doktorun yanında ă̆ladım. Bakın hala elim titriyor anlatırken. Biz daha önce defalarca doktora gittik. Hatta bir seferinde psikoloğa gittik. Psikolog benden sonra eşime demiş ki senin çocŭ̆un normal, eşini psikiyatriste götür." (Anne-4/35)

"Açıkçası bir profesöre gitmiştik ilk. Özel muayenehanesine. [...] ...bize sorular sordu, biz de çocuğumuzun olumsuz yönlerini anlattık. Çocuğumuzu görmemişti ve 10-15 dakika sonra çocuğunuz otizmli demişti. Yani ben açıkçası inanamadım. Inanamadık. [...] Daha sonra farklı bir doktora gittik. $O$ da ben size net bir şey söyleyemem dedi. Otizmlidir veya değildir diyemem dedi. Belli bir yaşa geldikten sonra ancak bunu söyleyebilirim dedi." (Baba-4/39)

Ailelerin ilk etapta kısa bir muayene sonucunda çocukları için otizm tanısı konulmasının şok edici bir durum olduğunu ve tanı için farklı profesyonellere yöneldiklerini belirtmişlerdir. Tanının kendilerine söylenmesi ile birlikte şokla birlikte çaresizlik hissini yaşadıklarını ifade eden aileler bu durumu "duvara toslamak" olarak betimlemişlerdir. Otizmli olduğu düşünülen çocuk farklı uzmanlar tarafından farklı değerlendirmelere tabi tutulmakta, bu durum ise aileyi hem duygusal 
anlamda hem de maddi anlamda oldukça yıpratabilmektedir. Aileler doktorların çocuklarıyla ilgili kendilerinden 10-15 dakika içerisinde aldıkları bilgiler doğrultusunda tanı koyduklarını ve bu kısa tanılama sürecinin kendilerinde güvensizliğe sebep olduğu bildirilmiştir.

Ayrica ailelerin tanılama sürecinde ortalama 4-5 uzmana başvurdukları ve ortalama 3 yıl zaman geçirdikleri belirtilmektedir (Keen, Couzens, Muspratt and Rodger, 2010; Ailing-Moh and Magiati, 2012). Tüm bunlar ailelerin tanı ve dolayısıyla erken müdahalede gecikmeler yaşamalarına sebep olmaktadır.

"Ve ilk tanıyı aldığımızda biz Adana'da aldık ilk tanıyı aynen şu kelimeyi söylediler bize formu doldurdular doktor kalemi bıraktı çocuğunuz otizm dedi atipik otizm. Bu çocuk kendi başına yemeğini yiyemez kendi başına tuvaletini yapamaz hayatın idame ettiremez ne yaparsanı yapın dedi. Yani dünyamız yıkıldı Adana'dan gelene kadar ben ağladım hiç durmadım." (Anne-1/53)

"Götürmediğim doktor kalmadr. Gaziantep'te bir Doçent var dediler ona götürdük. Oradaki doçente şunu söyledim. Ben çocuğumun otizmli olduğuna inanmıyorum. Dedi ki siz dedi, öncelikle bunu kabul edin, çocuğunuzun hasta olduğunu kabul edin. 1 yaşındayken annem dedi ki; oğlum bu çocuk normal değil, bir doktora götür. Bunu söyledikten sonra annemin kalbini kırdığımı hatırliyorum." (Baba-5/48)

Aileler tanıyı kabullenmekte zorlandıkları için farklı profesyonellere gitse de bazen durumun çok da ciddi olmadığı veya belirtiler hafifletilerek anlatıldığ1 için sonrasında tanı ile karşılaştıklarında şok yaşamakta ve kabullenmekte zorlanmaktadır. Bazı ailelerin çocuklarıyla ilgili kendilerini uyaran yakınların dahi dinlemek istemedikleri ve bazen onlardan uzaklaştıkları görülmektedir.

Tanı Sonrası Yaşanan Zorluklar: Tanı sonrasında ebeveynlerin ne yapacaklarını bilmeyişleri, öncelikle hangi müdahalenin gerçekleştirilmesi gerektiği, özel eğitimin yoğunluğunun ne kadar olacağı, yaşanılan bölgede özel eğitim ve benzeri hizmetlere erişmede yaşanan zorluklar, ailenin günlük rutinleri ve planlarının tamamen çocuğa endeksli hale gelmesiyle birlikte iş hayatı ve eğitim hayatının sekteye uğraması gibi zorluklar, ailelerin bu anlamda karşı karşıya kaldıkları zorluklar arasındadır. Ayrıca ailelerin tanı sonrasında maddi 
ve manevi olarak enerjilerini bir anda tamamen çocuklarının "otizmi aşması" umuduyla harcamaları, aileler için bir diğer zorluktur.

"Tamamen *** odaklı yaşıyoruz zaten. Onun kendi başına ayakta kalabilmesi için çalışmalarımız, eğitimlerimiz, düzenimiz her şeyimiz ona göre değişti. Biz bir de diyete başladık. Diyetle birlikte rutinlerimiz günlük ***'un istediği gibi olmaya başladı. Sabah kahvaltısını yapar, oyunları oynanır, yapılacak diğer birkaç etkinlik yaparız. [...] Evde televizyonu falan kaldırdık, sürekli eğitimlere başladık, eve özel öğretmen tuttuk. (Anne-2/34)

"Şimdi ben çocuğumla ilgileniyordum ama tanıdan sonra daha çok ilgilenmeye başladım. Hatta arkadaşlarım bile şey diyorlard, ya biz senin çocuğunla ilgilendiğinin onda biri kadar kendi çocuğumuzla ilgilenmiyoruz. Çocuğumla geçirdiğim vakit hayli arttı, işe yönelik yoğunluklarım azaldı. Mesela ben ful ek ders alıyordum onu azalttım." (Baba-2/38)

"Tabi o stralar bizim çocuğumuz oldu, bir kız çocuğumuz oldu. Aslında biz tanı almadan kızıma hamileydim. Doğduktan sonra tanı aldık. Bilmiyorum belki de tanı alsaydık ikinci bir çocuk düşünmezdik sanırım." (Ann-4/35)

Aileler tanı sonrasında günlük rutinlerinin büyük oranda değiştiğini, çalışma hayatından sosyal hayata kadar birçok alandan geri çekilen aileler, zamanlarının büyük kısmını çocuklarına ayırmaya başlamışlardır. Ailelerin çocuk sahibi olmayla ilgili planlarının dahi tanı sonrası değişebileceği aileler tarafından ifade edilmiştir.

"IŞ hayatımı, anında zaten bitirdim. Sosyal hayatımı bitirdim yani bu derneği kurana kadar ben hiçbir şekilde sosyal hayat falan hiç olmad. Yani günün 24 saati ben oğlumla beraberdim. Ondan sonra oğlum biraz daha iyi gitmeye başlayınca acaba ben diğer çocuklar için ne yapabilirim diye düşünmeye başladık derneği kurduk yani elimizden geldiği kadar insanları bilgilendirmeye ailelere destek olmaya çalışıyoruz." (Anne-1/57)

"Yani mesela ben kendim özel sektörde olduğum için çocuğuma biraz daha zaman ayırabilmek için personel sayısını artırdım. Eşim işten çıkmadı ama uzunca bir süre suçluluk hissetti. Başka çocuklara eğitim verirken kendi çocuğumu ihmal mi ettim diye düşündü. Bir ara öğretmenliği bırakmayı düşündü. Ama daha sonra vazgeçti." (Baba-4/39)

Aileler tanı sonrasında özellikle çalışma hayatları ile ilgili radikal değişimler yaşadıklarını, işi bıraktıklarını, bırakmasalar dahi zaman zaman suçluluk hissettiklerini belirtmişlerdir. 
"Bu çocuk eğitim alacak, rapor çıktı ama nereye kadar gidecek. Bunun okul hayatı var, ilkokulda mesela şu an 3. sinıf öğrencisi. Ortaokulda ben ne yapacağım, lisede ben ne yapacă̆ım. Yani ilerisi hakkında fazla bir plan yapamıyorsunuz Yani kısa vadeli düşünüyorsunuz, nereye kadar gideceğini bilmediğiniz için." (Anne-4/35)

"Sadece çocuğumu düşündüm. İlk tanıyı 3 yaşında, 4 yaşında aldık ve biz o yaşlarda kabul ettik. Fakat şunu söyleyeyim. Ben oğlumu üç yıl aralıksız her hafta Hatay'a götürdüm. Rehabilitasyon merkezine götürdüm. Kahramanmaraş'ta yok muydu? Vardı ama hepsi ticaret üzerine, para üzerine, rant üzerine kurulmuş tesisler, kuruluşlar." (Baba-5/48)

“...yetmedi biz Ankara'ya gidiyoruz. Ankara'da bir özel eğitim merkezine başladık. Şehir dışında özel eğitime 6 ay falan gittik. Haftada bir gün gidebiliyoruz Ankara'ya. Onda da iki saat bireysel eğitim alıyoruz, bir saat ergoterapi alıyoruz. Daha önce bir de dil terapisi alıyorduk ama hem uzaktan geldiğimiz için o kadar ders saati çocuğuma uygun olmadı, zorlanmaya başladı" (Anne-2/34)

"Otizmli bir çocuğa sahipseniz bir kere özel eğitim masrafinız var. Bir de küçük bir şehirde yaşıyoruz biz. Buradaki özel eğitimlerin yetersizliğinden dolayı Büyükşehir'e gitmek zorunda kalıyoruz. İşte gidiş-geliş, oradaki eğitim masrafları." (Baba-4/39).

Tanı sonrasında kimi ailelerde ne yapacağını bilmeme ya da ilerleyen yıllarda ne gibi şeylerle karşılaşılacağını bilmeme ciddi bir sorun olarak karşılarında durmaktadır. Ayrıca ailelerin ne yapacaklarını bilseler dahi bulundukları şehirlerde "iyi" olarak niteleyebilecekleri özel eğitim ve rehabilitasyon merkezlerinin olmayışından dolayı şehir dışında çıkmak zorunda kalmaları da aileler için maddi ve manevi açıdan oldukça yıpratıcı bir süreç olmaktadır.

Toplumsal Kabul ile İlgili Zorluklar: Ailelerin yaşadığı zorluklardan biri de toplumsal kabul ve sosyal destek ile ilgilidir. Aileler sürecin başından itibaren bazen tercihen bazen de toplum tarafından izole edilmektedirler. Aileler tanı sonrasında yalnız kaldıklarını, büyük oranda geniş aile üyeleri tarafından dahi desteklenmediklerini, arkadaş ve akraba ile ilişkilerinin zayıfladığını, sosyal yaşantılarının bittiğini belirtmişlerdir. $\mathrm{Bu}$ durum ebeveynlerin çevreden gelecek tepkiler dolayısıyla kendilerini 
izole etmeleri ile ilgili olduğu gibi çevredeki insanların ailelerden uzaklaşmaları ile de ilgilidir.

"Toplumun içerisinde bizim de var olduğumuzu insanlar kabullenmiyor. Bize öcü gibi bakıyorlar bize. Zannediyorlar ki bu insanlar gelip bizi ısıracak, zannediyorlar ki gelip bu insanlar bize vuracak, zannediyorlar ki bu insanlar uzaydan gelmiş. Bizim onlardan uzaklaşmamızı istiyorlar. Bugün belediye otobüsüne binsek herkes dönüyor, 40 kişi dönüp bize bakıyor. Tüm gözlerin sizin üzerinizde olması ne kadar rahatsız edici düşünebiliyor musunuz" (Baba1/57)

"Insanların bizlere karşı bakışlarından rahatsız oluyoruz. Sorduğu sorulardan rahatsız oluyoruz. Her eve geldiğimde bir daha çocukla dişarı çıkmayacă̆ım diyorum. Bazen insanlar ters karşılıyor. O zoruma gidiyor. Çocuğun bir art niyeti olmamasına rağmen insanlar ters tepki verdiğinde zoruma gidiyor. Ama bazı insanlar çok anlayışlı melek gibiler." (Baba-2/38)

"Gittiğimiz yerlerde bir de ister istemez stereotipik hareketleri var. Ses çıkarma olayımı var. Bir AVM'ye bile gittiğimiz zaman farklı bir tavır sergilediği zaman dönüp bakıyorlar. Fiziksel olarak bir farklılı̆̆ı yok ama öyle olunca da ister istemez çıkmamayı tercih ediyoruz. Yani insanlara bir şey anlatmaktansa geri planda kalmayı tercih ediyoruz." (Anne-2/34)

Aileler toplum içerisinde çocukları dolayısıyla kendilerine yöneltilen bakışlardan rahatsız olduklarını, kimi zaman çocuklarıyla dışarı çıkmak istemeyecek hale geldiklerini, bu bakışlara maruz kalmak yerine dışarı çıkmamayı tercih ettiklerini belirtmişlerdir.

"Bütün okulları gezdim. Hiçbir öğretmen ben böyle bir çocuğu kabul ederim demedi. Hiçbiri kabul etmedi. [...] Bacım öğretmen, bacım dahi kabul etmedi. Sonra halamın kızı öğretmen, belki ben kabul edebilirim, ben idealist bir öğretmenim dedi. İealistlik sınıfındaki çocukları birinci çıkartmakla olmuyor maalesef." (Baba-5/48)

"Bizim otizmli aileler olarak, şahsıma konuşmuyorum genel olarak konuşuyorum. Hiçbir aile akrabasından, yakınından, en yakın kardeşi ve kız kardeşi, kardeşlerinden veyahut da dayısından hiç kimse destek almamıştır. Aldım diyorsa da yanıldı̆̆ııı düşünüyorum. [...] Şu anda biz aile olarak kimiz biliyor musunuz? Bir çocuk, bir anne, bir ben. Diğerleri sadece ve sadece Allah yardımcınız olsun, siz cennetliksiniz deyip geçiyorlar."(Baba-1/57)

"Arabayla kaza yaptık, 3 gün sanayide kaldı araba. Kardeşim arabasın vermiyor, bacım arabasını vermiyor. Yani kardeşim fabrikada çalışıyor sabahtan 
akşama kadar araba kapının önünde, binmiyor zaten. Vermiyorlar yani. Nasıl bir yapı anlamış değilim" (Baba-5/48)

Tanı sonrası en yakın aile üyeleri tarafından dahi desteklenmediklerini belirten aileler bazı ihtiyaçlar için kendilerine destek vermeyen ailelerin bu tavırlarına anlam vermediklerini ve en nihayetinde yalnız olduklarını düşündüklerini ifade etmişlerdir.

\section{Tartışma ve Sonuç}

Araştırmada otizmli çocuğa sahip ailelerin otizmli çocuğa sahip olmaktan dolayı karşı karşıya oldukları zorlukların neler olduğu ve bu durumun aile dinamiklerini nasıl etkilediği incelenmiştir. Aileler otizmli bir çocuğa sahip olmaktan dolayı stres yükü altındadırlar. Bu stresin kaynağı başta bakım yükü olmak üzere çocuklarının ihtiyaçlarını karşılamayla ilgilidir. Son meta analizler ve meta-sentezler, otizmli çocuğa sahip ebeveynlerin, tipik olarak gelişen çocuklara ve diğer engelli çocukların ebeveynlerine kıyasla daha fazla ebeveynlik stresi yaşadığını desteklemektedir. $\mathrm{Bu}$ stres sıklıkla çocuklarının ihtiyaçlarını karşılamanın zorluğu ile ilgilidir (Hayes and Watson, 2013; Ooi, Mehmood, Khan and Tahir, 2016). Çalışmamıda literatüle benzer şekilde ebeveynlerin otizmli çocuklarının başta bakım olmak üzere diğer ihtiyaçlarını karşılama noktasında eksiklikler ve zorluklar yaşadıkları, bu durumun ise onların yaşadığı ebeveynlik stresinin artmasına neden olduğu ortaya konmuştur.

Aileler ilk olarak farkındalık sürecinde çeşitli zorluklar yaşamaktadırlar. Çocuklarındaki farklılıkları hisseden aileler genellikle bu durumun geçici bir durum olduğunu düşünmekte ve tanı konusunda gecikmektedirler. Bu durum ailenin kabulü ile ilgili olduğu gibi çevreden gelen tepkilerle de ilgilidir. Özellikle otizm hakkında bilgi sahibi olmayan geniş aile üyelerinin, ebeveynleri bu durumun geçici bir durum olabileceği ve çocuklarının "normal" olduğu yönündeki söylemleri, ailenin şüphe duyması ile tanı aşamasına geçiş sürecini uzatmaktadır. Bu durum literatürdeki diğer çalışmaları doğrular niteliktedir. Wiseman (2009) farkındalık sürecinde kimi ailelerin tanı sürecinde yapılacak uygulamaları vakit kaybı olarak görebildiğini, yanlış yönlendirmeler neticesinde sorunun geçici olabileceğini düşünerek 
kapsamlı bir değerlendirme sürecine dahil olmamadıklarını bilirmiştir (Wiseman, 2009)

Aileler farkındalık aşamasından tanılama sürecine geçtiklerinde ise doğru tanılamaya ulaşma ve farklı profesyonellerden farklı değerlendirmeler almayla ilgili zorluklarla karşı karşıyadır. Bu süreçte aileler kimi zaman daha iyimser söylemler duyarken bazen de oldukça kötümser söylemlere maruz kalabilmektedirler. Bu durum ise ailelerde kafa karışıklığına yol açtığı gibi aileyi duygusal ve maddi anlamda yormaktadır. Yapılan bir çalışmada ailelerin tanılama sürecinde ortalama 4-5 uzmana başvurdukları ve ortalama 3 yıl zaman geçirdikleri belirtilmektedir (Keen, Couzens, Muspratt ve Rodger, 2010). Howlin ve Moore (1997) İngiltere'de 1200 aile ile yapmış oldukları çalışma neticesinde ailelerin yaklaşık yarısının (\%48) ilk 24 ay içerisinde ortalama ise 1,69 yaşında şüphe duymalarına rağmen tanının ortalama 5 yaşında konduğunu ortaya koymuşlardır (Howlin and Moore, 1997, s.142). Çalışmamıza katılan ailelerin benzer şekilde tanı sürecinde farklı profesyonellere gitme ve "doğru" tanıyı alma konusunda yoğun bir çaba harcadıkları ve bu sürecin onlar için oldukça yorucu olduğu ortaya konmuştur.

Otizmli bir çocuğa sahip olmak aile içi ilişkileri de ciddi anlamda etkilemektedir. Çiftler tanı sonrasında suçluluk ve depresyon aşamalarına ek olarak kimi zaman birbirlerini suçlayabilmektedirler. Kimi zaman boşanmaya kadar varan aile içi ilişkilerdeki çatışmanın nedenleri arasında ailenin çocuğa 7 gün 24 saat olacak şekilde bakım verme gibi bir bakım yükü altında olması, tanı sonrası ebeveynlerin başta çalışma hayatı ile sosyal hayatında yaşanan radikal değişimler, çocuğun bakım, tedavi, eğitim ve diyetleri için ailenin ciddi bir finanasal yük altına girmek zorunda kalması sayılabilir. Bu durum alanyazında yer alan çalışmalarla benzerlik göstermektedir. 2010 yılında ABD'de otizmli çocuğa sahip 391 ebeveyn ile gerçekleştirilen bir çalışmada otzmli çocuğa sahip çiftlerin boşanma olasılı̆̆ı, otizmli çocuğu olmayan çiftlerle karşılaştırılmış ve \%23,5'e \%13,8'lik bir oran olduğu ortaya konmuştur (Hartley, ve diğerleri, 2010, s.452). Yapılan diğer bir araştırmada otizmli çocuğa sahip ebeveynlerin, aile ve evlilik ilişkilerinde engeli olmayan çocukların ebeveynlerine göre daha fazla zorluk yaşadıkları, daha düşük aile uyumu ve evlilik memnuniyetine 
sahip oldukları ve birbirlerine daha az sevgi ifadeleri kullandıkları bildirilmiştir (Gau, ve diğerleri, 2012).

$\mathrm{Bu}$ anlamda otizmli çocuklarla ilgili etkili müdahaleler ve sağlanacak destekler hem çocuğun hem de ailenin iyilik halinin devamı için oldukça önemlidir. Bu doğrultuda başta farkındalık sürecinin hızlı bir şekilde tanı aşamasına geçişinin ağlanabilmesi adına farkındalık çalışmalarının arttırılması ve ailenin dolayısıyla toplumun otizmle ilgili bilinç ve farkındalık düzeyinin arttırılması gerekmektedir. Tanı aşamasında doğru tanıya ulaşma konusunda ailelere verilecek danışmanlık hizmetleri tanıdaki gecikmeleri önleyeceği gibi erken müdahaleyi de hızlandıracaktır. 
EXTENDED ABSTRACT

\title{
The Experiences of Families with Autistic Children with Their Difficulties
}

\author{
* \\ Ferhat Toper-Yasemin Özkan \\ Malatya Turgut Ozal University- Hacettepe University
}

\section{Background}

Autism spectrum disorder is a neuro-developmental disorder whose symptoms appear in early childhood and whose effects last a lifetime, negatively affecting social interaction and communication skills. Many ideas have been put forward regarding the cause of autism. Some researchers have claimed that functional disorders in the region of the brain where stimuli from the environment are processed and damage in the temporal region of the brain may cause autism. Another issue related to autism is the prevalence of autism and its extraordinary increase in recent years. It is known that autism is the most common developmental disorder after intellectual disability. The extraordinary increase in the prevalence of autism since the 1960s has attracted the attention of many different social science researchers, especially medicine and psychology. The first study on the prevalence of autism was made in 1966, and in this first study, the prevalence of autism was found to be 4.5 per 10,000. Since autism affects all family members at certain levels rather than being an individual developmental disorder, studies on autism often focus on the effect of autism on the family system. In general, it is preferable for a new member to join the family and to ensure the adaptation of this new member to the family as soon as possible, but this is not always possible. Particularly, the joining of an individual with a disability to the family often becomes a difficult process for families. This situation emerges as a source of stress as it puts much more responsibility on the family. Purpose

The aim of the study is to reveal the effect of having a child with autism on family dynamics and the difficulties experienced by family members. In addition, understanding the psychological, social and 
financial effects of raising a child with autism for families and revealing the consequences for families are among the aims of the research. It is also among the aims of the research to determine how parents are affected physically, emotionally and mentally because of having a child with autism.

\section{Method}

The research was designed as a qualitative research in order to reveal the experiences of families with autistic children regarding the psychological and social difficulties they experience. The phenomenological approach, which is one of the qualitative research designs, was used in the research. The phenomenological approach is an approach that deals with the experiences of a group of people on a particular subject. Purposive sampling was used to determine the study group to participate in the research. In this context, the study group of the research consists of 10 parents with a child with autism. The criteria for determining the study group were that the parents had a medical diagnosis of autism for their children and that their children were younger than 18 years of age. In the research, a socio-demographic characteristics form consisting of 16 questions prepared by the researcher and a semi-structured interview form consisting of 25 questions prepared by the researcher were used. . Interviews with the parents were recorded via smartphone and the voice recordings of the 10 interviewed parents were transcribed. The data was then transferred to the MAXQDA 2020 program. An inductive approach has been adopted in the analysis process of the data transferred to the MAXQDA 2020 program. The data was read many times and the first codes were created. Then, related codes were grouped under themes and named. The themes obtained are explained in a language that is parallel and understandable with the literature.

\section{Findings}

The data obtained within the scope of the research were transferred to the MAXQDA 2020 Qualitative analysis program, and code lists were created by reading all the data from beginning to end. The generated 
code lists were then categorized and three main themes were determined. These themes are the difficulties experienced by families with autistic children before and during diagnosis, difficulties experienced after diagnosis, and difficulties related to social acceptance. Parents have doubts about the difficulties experienced before and during the diagnosis, and difficulties in entering the diagnosis process after suspicion, the lack of clarity about the diagnosis, the diagnosis being told directly to them, the fact that the diagnosis is not clearly expressed most of the time, and the family's concerns about autism. They mentioned various difficulties, ranging from lack of knowledge. In this sense, the prolongation of the diagnosis process, the family's shock at the first moment of the diagnosis, the reactions given to the words heard from the extended family members about the diagnosis, the time spent applying to different professionals to hear something different, and the uncertainty of the family during this period can be counted among the main difficulties. Families who stated that they experienced the feeling of helplessness along with shock after being told the diagnosis to them described this situation as "hitting a wall". The child, who is thought to have autism, is subjected to different evaluations by different experts, and this situation can wear down the family both emotionally and financially. After the diagnosis, parents do not know what to do, which intervention should be carried out first, how intense the special education will be, difficulties in accessing special education and similar services in the region where they live, and the interruption of work and education life as the daily routines and plans of the family become completely dependent on the child. difficulties are among the difficulties faced by families in this sense. In addition, it is another challenge for families to spend their financial and moral energies after the diagnosis in the hope that their children will "overcome autism". One of the difficulties faced by families is related to social acceptance and social support. Families are isolated from the beginning of the process, sometimes preferably by the society. Families stated that they were left alone after the diagnosis, they were not supported even by their extended family members, their relations with friends and relatives weakened, and their social life ended. This situation is related to the 
isolation of the parents due to the reactions from the environment, as well as the separation of the people from the family.

\section{Conclusions}

In the study, the difficulties faced by families with autistic children due to having a child with autism and how this situation affects family dynamics were examined. Families are under stress because of having a child with autism. The source of this stress is related to meeting the needs of their children, especially the burden of care. Families first experience various difficulties in the awareness process. Families who feel the differences in their children generally think that this is a temporary situation and they delay in diagnosis. This is related to the acceptance of the family as well as the reactions from the environment. When families move from the awareness stage to the diagnosis process, they face difficulties in reaching the correct diagnosis and getting different evaluations from different professionals. In this process, families can sometimes hear more optimistic statements, and sometimes they can be exposed to quite pessimistic statements. This situation causes confusion in families and exhausts the family emotionally and financially. Having a child with autism also seriously affects family relationships. In addition to the stages of guilt and depression after the diagnosis, couples can sometimes blame each other. Among the reasons for the conflict in the family relations, which sometimes leads to divorce, the family is under a care burden such as caring for the child $24 / 7$, the radical changes in the working and social life of the parents after the diagnosis, the care, treatment, education and diet of the child. It can be considered that the family has to bear a serious financial burden.

\section{Kaynakça / References}

Ailing-Moh, T. and Magiati, I. (2012). Factors associated with parental stress and satisfaction during the process of diagnosis of children with Autism Spectrum Disorders. Research in Autism Spectrum Disorders, 6(1), 293-303.

Baird, G., Simonoff, E., Pickles, A., Chandler, S., Loucas, T., Meldrum, D. and Charman, T. (2006). Prevalence of disorders of the autism spectrum in 
a population cohort of children in South Thames: the special needs and autism project (SNAP). Lancet, 268(9531), 210-215.

Baker, S. M. (2013). Learning about autism. Global Advances In Health And Medicine, 2(6), 38-46.

Benderix, Y., Nordström, B. and Sivberg, B. (2006). Parents' experience of having a child with autism and learning disabilities living in a group home. A case study. Autism, 10(6), 629-641.

Bilgiç, A. ve Cöngöloğlu, A. (2009). Otizm spektrum bozukluklarında biyolojik temelli tamamlayıcı ve alternatif tıp uygulamaları. Çocuk ve Gençlik Ruh Sağhlğ ı Dergisi, 16(3), 153-164.

Coren, L. A., Najjar, D. V., Ray, G. T., Lotspeich, L. and Bernal, P. (2006). A comparison of health care utilization and costs of children with and without autism spectrum disorders in a large group-model health plan. Pediatrics, 118(4), 1203-1211.

Creswell, J. W. (1994). Research design: Qualitative $\mathcal{E}$ quantitative approaches. New York: Sage Publications Inc.

Dyches, T. T., Wilder, L. K., Sudweeks, R. R., Obiakor, F. E. and Algozzine, B. (2004). Multicultural issues in autism. Journal of Autism and Developmental Disorders, 34(2), 211-222.

Fletcher, P. C., Markoulakis, R. and Bryden, P. J. (2012). The costs of caring for a child with an autism spectrum disorder. Comprehensive Child and Adolescent Nursing, 35(1), 45-69.

Frith, U. (2008). Autism: A very short introduction. Oxford: Oxford University Press.

Gau, S. S.F., Chou, M.C., Chiang, H.L., Lee, J.C., Wong, C.C., Chou, W.J. and $\mathrm{Wu}$, Y.-Y. (2012). Parental adjustment, marital relationship, and family function in families of children with autism. Research in Autism Spectrum Disorders, 6(1), 263-270.

Gupta, V. B. (2007). Comparison of parenting stress in different developmental disabilities. Journal of Developmental and Physical Disabilities, 19(4), 417425.

Hartley, S. L., Barker, E. T., Seltzer, M. M., Floyd, F., Greenberg, J., Orsmond, G. and Bolt, D. (2010). The relative risk and timing of divorce in families of children with an autism spectrum disorder. Journal of Family Psychology, 14(4), 449-457.

Hayes, S. A. and Watson, S. L. (2013). The impact of parenting stress: a metaanalysis of studies comparing the experience of parenting stress in 
parents of children with and without autism spectrum disorder. Journal of Autism and Developmental Disorders, 43(3), 629-642.

Howlin, P. and Moore, A. (1997). Diagnosis in autism: A survey of over 1200 patients in the UK. Autism, 1(2), 135-162.

Kaya, Ö. (2016). Otizm spektrum bozukluğu olan bireylerin değerlendirilmesi. Ş. Y. Özkan, Y. Ergenekon, A. Çolak ve Ö. Kaya içinde, Otizm Spektrum Bozukluğu (s.59-92). Ankara: Grafiker Yayınları.

Kayaoğlu, H. ve Görür, Ö. (2008). Otistik çocuklar nasıl öğrenir? Ankara: Epsos Yayınları.

Keen, D., Couzens, D., Muspratt, S. and Rodger, S. (2010). The effects of a parent-focused intervention for children with a recent diagnosis of autism spectrum disorder on parenting stress and competence. Research in Autism Spectrum Disorders, 4(2), 229-241.

Köse, S., Özbaran, B ve Erermiş, S. (2012). Otizm yelpaze bozukluklarında nöropsikolojik profil. Çocuk ve Gençlik Ruh Sağhlğı Dergisi, 19(2), 103115.

Kuckartz, U. and Rädiker, S. (2019). Analyzing qualitative data with MAXQDA. USA: Springer.

Kuhn, R. and Cahn, C. H. (2004). Eugen Bleuler's concepts of psychopathology. History of Psychiatry, 15(3), 361-366.

Lee, L.-C., Harrington, R. A., Louie, B. B. and Newschaffer, C. J. (2008). Children with autism: Quality of life and parental concerns. Journal of Autism and Developmental Disorders, 38(6), 1147-1160.

Lotter, V. (1966). Epidemiology of autistic conditions in young children. Social Psychiatry, 1(1), 124-137.

Marcus, L. M., Kunce, L. J. and Schopler, E. (2005). Working with families. F. R. Volkmar, R. Paul, A. Klin and D. Cohen içinde, Handbook of Autism and Pervasive Developmental Disorders, Assessment, Interventions, and Policy (Volume 2) (s. 1055-1085). New Jersey: John Wiley \& Sons, Inc.

McGrath, P. (2006). Psychosocial issues in childhood autism rehabilitation: A review. The International Journal of Psychosocial Rehabilitation, 11(1), 2936.

Midence, K. and O'Neill, M. (1999). The experience of parents in the diagnosis of autism. Autism, 3(3), 273-285.

Morse, J. M. (2016). What is qualitative research? Qualitative Health Research, 25(1), 859-860. 
Newschaffer, C. J., Croen, L. A., Daniels, J., Giarelli, E., Grether, J. K., Levy, S. E., . . C.Windham, G. (2007). The epidemiology of autism spectrum disorders. Annual Review of Public Health, 28, 235-258.

Ooi, K. L., Mehmood, Y. S., Khan, S. A. and Tahir. (2016). A meta-synthesis on parenting a child with autism. Neuropsychiatric Disease and Treatment, 5(12), 745-762.

Patton, M. Q. (2014). Qualitative research \& evaluation methods. California: Sage Publications.

Rogge, N. and Janssen, J. (2019). The economic costs of autism spectrum disorder: A literature review. Journal of Autism and Developmental Disorders, 49(7), 2873-2900.

Wiseman, N. D. (2009). The first year: Autism spectrum disorders: An essential guide for the newly diagnosed child. Pennsylvania: Da Capo Press.

Yılmaz, M. and Atalar, U. (2021). Otizmli kardeşe sahip çocukların yapısal aile terapisi. Insan ve Toplum Bilimleri Araştırması Dergisi, 10(1), 590-604.

Yüksel, A. (2005). Otizm genetiği. Cerrahpaşa Tip Dergisi, 22(1), 35-41.

\section{Kaynakça Bilgisi / Citation Information}

Toper, F. ve Özkan, Y. (2021). Otizmli çocuğa sahip ailelerin yaşadıkları zorluklara ilişkin deneyimleri. OPUS-Uluslararası Toplum Araştırmaları Dergisi, 18(43), 6682-6707. DOI: 10.26466/opus.923379. 